Association for Information Systems

AIS Electronic Library (AISeL)

Wirtschaftsinformatik 2021 Proceedings

Track 5: Digitization and society - even in times

of Corona

\title{
Designing Online Platforms for Cultural Participation and Education: A Taxonomic Approach
}

\author{
Kristin Kutzner \\ Universität Hildesheim \\ Thorsten Schoormann \\ Universität Hildesheim \\ Claudia Roßkopf \\ Universität Hildesheim \\ Ralf Knackstedt \\ Universität Hildesheim
}

Follow this and additional works at: https://aisel.aisnet.org/wi2021

Kutzner, Kristin; Schoormann, Thorsten; Roßkopf, Claudia; and Knackstedt, Ralf, "Designing Online Platforms for Cultural Participation and Education: A Taxonomic Approach" (2021). Wirtschaftsinformatik 2021 Proceedings. 1.

https://aisel.aisnet.org/wi2021/VDigitization/Track05/1

This material is brought to you by the Wirtschaftsinformatik at AIS Electronic Library (AISeL). It has been accepted for inclusion in Wirtschaftsinformatik 2021 Proceedings by an authorized administrator of AIS Electronic Library (AISeL). For more information, please contact elibrary@aisnet.org. 


\title{
Designing Online Platforms for Cultural Participation and Education: A Taxonomic Approach
}

\author{
Kristin Kutzner ${ }^{1}$, Thorsten Schoormann ${ }^{1}$, Claudia Roßkopf ${ }^{2}$ and Ralf Knackstedt ${ }^{1}$ \\ ${ }^{1}$ University of Hildesheim, Institute for Economics and Information Systems, Hildesheim, \\ Germany \\ \{kristin.kutzner,thorsten.schoormann, ralf.knackstedt \}@ uni-hildesheim.de \\ ${ }^{2}$ University of Hildesheim, Institute for Cultural Policy, Hildesheim, Germany \\ \{claudia.rosskopf\}@uni-hildesheim.de
}

\begin{abstract}
Museums preserve the cultural heritage and aim at providing study and education as well as enjoyment for the general public. In pursuing their missions, museums are increasingly concerned with making these experiences digitally available. Therefore, they start to use online platforms that make cultural objects publicly accessible, and therefore allow discussing cultural issues and provide cultural and educational participation. However, as there is little consolidated knowledge on features of such platforms and limited resources of museums, they face challenges in achieving their missions through a platform. In order to overcome this, we (1) review and synthesize related literature and online platforms and (2) present a taxonomy of how online offers leverage cultural participation and education. In doing this, we seek to enable platform designers and museum professionals in making informed decisions in terms of how the 'museum experience' can be supported/complemented through online platforms.
\end{abstract}

Keywords: Cultural Access, Museum, Society, Digital Inclusion, Taxonomy.

\section{Introduction}

According to the International Council of Museums [1], a museum's core mission is to provide study, education, and enjoyment for the general public. By collecting, preserving, exhibiting and interpreting the humanity's heritage, they allow individuals to take part in cultural activities and experiences (i.e., cultural participation) and thus aim to foster social justice and well-being [2]. Along with this, museums allow education for individuals which means reflecting on oneself, others and issues of the world [3] as well as taking critical position towards knowledge, artist experiences and cultural objects [4]. Since museums play a fundamental role in our society, their services should be affordable and equal accessible for everyone. This is however often not the case because of various (individual, social or environmental) obstacles such as time restrictions, geographical distances, financial resources, language barriers, physical handicaps, health reasons, or even global pandemics. One way for museums 
to cope with these obstacles is given by the use of digital technologies and the Internet, which is in line with the Director of National Museums in Seychelles Beryl Ondiek's statement: "In the mist of chaos, museums break the walls that keep us apart. Museums can use all of the collections and information we have, and transmit our cultural and natural heritage to communities through the Internet to lift spirits and keep everyone connected." Accordingly, museums have started to consider the use of online platforms such as websites, social media, or blogs [5]. This practice enables museums to provide public access to the heritage, leverage cultural participation and mobilization in society as well as allows individuals to engage with and discuss cultural issues [6] - even in cases such as the Covid-19 pandemic that was the trigger for the closure of plenty of museum facilities in 2019/2020 [7].

Despite the great potential of using online platforms for cultural participation and education, their use is far from being fully exploited and museum professionals are usually unfamiliar with digital solutions accompanied by resource restrictions and fragmented know-how [8]. Furthermore, especially small and medium-sized institutions often struggle because of their dependence on public funding and volunteer work [9]. Even though previous research on this topic indicates the importance of digitization, they mostly focus on rather isolated aspects, for instance, the impact of museum websites on users [10] or guidelines for providing access to and presenting museum data $[9,11]$. In consequence, we lack knowledge of what platform features should be implemented to best possible support access to cultural participation and education. This lack is problematic as it hinders, for instance, museum professionalsin addition to limited resources and technical know-how-in improving their museum platforms to achieve their educational mission and to attract visitor attention. To bridge this gap, we seek to derive an overview of currently used platform features that act as a foundation for supporting online-based cultural participation and education. Therefore, we formulate the following research question (RQ): What are the characteristic features of online platforms for providing access to cultural participation and education in society?

To answer this question, we follow the procedure proposed by [12] and deduce a taxonomy of platform features for access to cultural participation and education. The taxonomy enables, for example, professionals in museums and in further institutions with cultural and educational missions such as theatres, libraries, or heritage centers to (a) be informed within the wide range of platform features to compare, refine and develop their online presence and (b) to make their services publicly accessible and participatory. Furthermore, the taxonomy can help to (c) improve marketing activities [5] and therefore to raise peoples' interest in visiting the institution [13] as well as to increase visitor numbers [14]-despite public sector cuts and financial pressure [14]. From a more societal view, disadvantaged individuals who cannot benefit from local cultural practices are supported in their cultural and educational participation. Based on the taxonomy, potential users (i.e., individuals) can select appropriate platforms for their personal purposes and, in the future, they will benefit from the enhanced landscape of online platforms for cultural participation. For research, the taxonomy can be used, for instance, to explore and advance (social inclusive) online platform designs that enable participating in culture as well as leveraging education. 


\section{Research Background}

The existing Information Systems (IS) research on museum online platforms can be grouped into four areas: (1) Research analyzed the influence of website design features on users. Surveying museum website users, [15] and [10] identified a set of requirements for encouraging enjoyable web experiences and informal online learning for users. In addition, [16] indicated that the use of game-based features led to enjoyment and learning. Furthermore, by examining two sample museum websites, studies discovered a positive influence of website features on users' intention to return to the website and to visit the physical museum [13, 14]. More general conclusions for museum websites are provided, however, the results are limited to the type of online platform. (2) Besides, research investigated guidelines for providing access to and presenting museum data. For example, a conceptual framework for visualizing museum data on mobile applications [9], an IS design theory for the interactive presentation and navigation of digital art collections [11] and a classification of information visualization approaches for digital cultural heritage collections [17] are proposed. These studies examined website features, however, they solely focused on the presentation of data on museum applications. (3) Moreover, research aimed at supporting the development of museum websites by proposing a five-step-procedure [18] and by presenting conceptual guidelines [10]. Nevertheless, both provided general guidance on museum website development without focusing on specific features. (4) In addition, the museums' attitude towards using features of online channels (i.e., social media and museum websites) was investigated which led to the conclusion that online participatory activity among museums was quite uniformed and restrained for technical reasons [5].

Overall, most studies focus on rather isolated aspects, address only a few sample platform features, or provide more general guidance for museums. In consequence, to the best of our knowledge, there is still a need for a comprehensive overview of platform features which allow cultural participation and education. In this study we seek to address this need by developing and evaluating a taxonomy of cultural participation and education in the digital age.

\section{Research Design}

The development of taxonomies is widely accepted in IS research regarding the design of online platforms/tools $[19,20]$ and in the context of culture [21-23] to structure, analyze and understand existing and future objects of a domain [12]. Taxonomies, as classified as 'theory for analyzing' [24], are a necessary foundation for developing advanced theories that, for instance, attempt to explain and predict how specific features will leverage the success of engaging in cultural practices. In this study, inspired by a staged approach [19], (Stage 1) we carried out a literature review and (Stage 2) identified relevant objects (i.e., online platforms that provide access to cultural participation and education). Following, based on the findings, (Stage 3) we iteratively built and (Stage 4) evaluated our taxonomy (Figure 1). 


\begin{tabular}{|c|c|c|c|}
\hline & Inputs & Methods/steps & Outputs \\
\hline $\begin{array}{c}\text { Stage 1: } \\
\text { Literature Review }\end{array}$ & $\begin{array}{l}\text { - Online publications } \\
\text { - IS research publications }\end{array}$ & $\begin{array}{l}\text { - Perform keyword search } \\
\text { - Analyse literature } \\
\text { - vom Brocke et al. (2009) }\end{array}$ & $\begin{array}{l}\text { - Research database that } \\
\text { met our research } \\
\text { purpose }\end{array}$ \\
\hline $\begin{array}{l}\text { Stage 2: } \\
\text { Selection } \\
\text { of Objects }\end{array}$ & $\begin{array}{l}\text { - Research database that } \\
\text { met our research } \\
\text { purpose }\end{array}$ & $\begin{array}{l}\text { - Perform Internet search } \\
\text { for online platforms }\end{array}$ & $\begin{array}{l}\text { - Online platform database } \\
\text { that met our research } \\
\text { purpose }\end{array}$ \\
\hline $\begin{array}{c}\text { Stage 3: } \\
\text { Taxonomy } \\
\text { Development }\end{array}$ & $\begin{array}{l}\text { - Research database and } \\
\text { online platform database } \\
\text { that met our research } \\
\text { purpose }\end{array}$ & $\begin{array}{l}\text { - Define dimensions } \\
\text { - Define characteristics } \\
\text { - Nickerson et al. (2013) }\end{array}$ & $\begin{array}{l}\text { - Taxonomy based on } \\
\text { conceptual and empirical } \\
\text { findings }\end{array}$ \\
\hline $\begin{array}{l}\text { Stage 4: } \\
\text { Taxonomy } \\
\text { Evaluation }\end{array}$ & $\begin{array}{l}\text { - Taxonomy based on } \\
\text { conceptual and empirical } \\
\text { findings }\end{array}$ & $\begin{array}{l}\text { Evaluate taxonomy } \\
\text { - Szopinski et al. (2019, } \\
\text { 2020) }\end{array}$ & $\begin{array}{l}\text { - Evaluated taxonomy of } \\
\text { digital cultural } \\
\text { participation and } \\
\text { education }\end{array}$ \\
\hline
\end{tabular}

Figure 1. Research design for developing the taxonomy

Stage 1: Literature Review. Firstly, we searched for prior literature dealing with museum online platforms based on the rigorous procedure of [25]. On February $12^{\text {th }}$ 2020 , to get an overview of research endeavors in the museum context in the IS domain, we searched for literature by using the keyword 'museum' in the AISeL database which covers leading IS outlets as well as publications related to our study's purpose such as with cultural and social media topics [26]. No limitation regarding the year of publication was made. As a result, we found 568 articles. As various studies used the term, however, did not focus on museums itself, we excluded articles that did not contain the term 'museum' in the title, abstract, or keywords. Finally, we obtained 41 articles. Reading each article in detail, we analyzed their research subjects and results. Based on this, we derived four main topics in IS research, appertaining to museum online platforms, namely, (1) the influence of website design features on users, (2) guidelines for providing access to and presenting museum data, (3) guidance for the development of museum websites, and (4) museums' attitude towards using features of online channels (see also Section 2, an appendix with details on relevant literature and related features can be made available upon request).

Stage 2: Selection of Objects. Secondly, we performed an Internet search for online platforms that provide access to cultural objects and allow participation. We chose museum websites as objects of investigation because museums, as players of cultural participation and education, make use of them to offer online access to cultural objects. To consider museums with comparable objects and (cultural-) political conditions, we decided to include German-speaking art museums that focus on visual arts and photography and that use digital solutions in particular. We chose this type of museum because art museums recorded particularly declining numbers of visitors in Germany [27] and thus could take advantage of the opportunities offered by digital solutions. Besides, museums expand their activities on rating platforms, for instance, as they present the museum on Google or TripAdvisor, where individuals can communicate and share their opinions or experiences with others. Furthermore, social media sites, 
such as Facebook and Twitter, are used by museums, to be present in the public, to provide current news, and to enable individuals to rate and discuss cultural objects. Moreover, blogs of art that are also referenced by museum websites, are an additional opportunity for presenting and discussing cultural objects. As all these platforms provide access to cultural objects and allow participation, we decided to include them, to get an overview of platforms. During the taxonomy development (see Stage 3), we iteratively selected additional platforms until there were no further changes in the taxonomy. As a result, we selected ten websites of German-speaking art museums, thirteen German-speaking art museums (partly museums whose websites were analyzed, but also other museums) at Google, TripAdvisor, Facebook, and Twitter as well as seven art blogs (see Table 1).

Table 1. Overview of selected online platforms

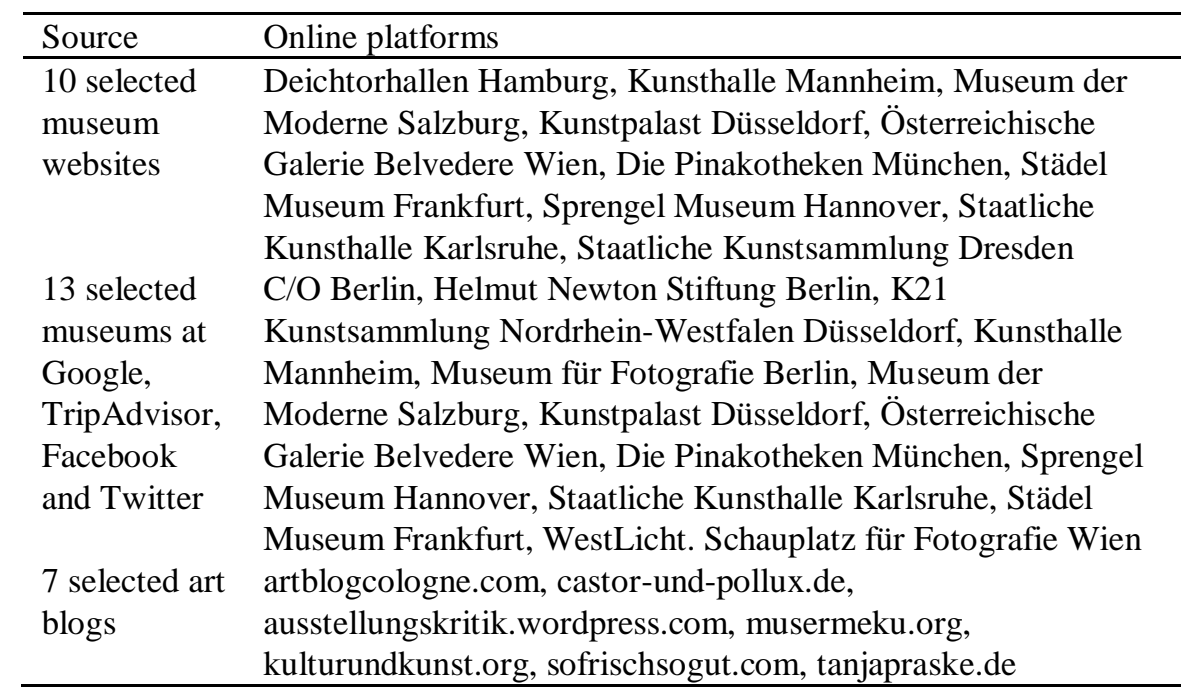

Stage 3: Taxonomy Development. Thirdly, to develop a taxonomy, we employed the systematic procedure proposed by [12]. As a first step, meta characteristics including the target users and purposes need to be specified. Our taxonomy may be potentially used by three target groups: (a) Researchers who are interested in designing online platforms that allow cultural access and participation as well as encourage education; (b) institutions with educational missions and cultural objects like museums, galleries, libraries, heritage centers who want to develop and refine their online platforms; (c) individuals who are interested in cultural participation but cannot participate locally because of individual obstacles and therefore select and use appropriate online platforms for their personal interest. The purpose is to build an overview of currently used online platform features that provide access to cultural participation and education. Thus, we aim to assist researchers and practitioners with the analysis and future development of cultural online platforms. To do so, the online platform features are particularly relevant, as these features determine the manner of access to cultural 
objects, and therefore, the possible degree of participation. Thus, we choose 'features of the platforms that are used to provide access to cultural participation and education' as meta-characteristics which must be met by all dimensions and characteristics. Next, to determine when to stop building the taxonomy, we adopted the objective ending conditions (i.e., determining when to terminate the taxonomy development) and subjective ending conditions (i.e., ensuring high quality while developing the taxonomy) proposed by [12], with one exception: The characteristics of each dimension are not mutually exclusive (i.e., unique) to offer multiple features for one dimension that can be used together on a platform as well as to reduce complexity and to support readability of the taxonomy (see also [28]).

Afterward, we ran through three empirical-to-conceptual iterations and one conceptual-to-empirical iteration and classified online platforms (Figure 2). We decided to start with the empirical-to-conceptual iteration because of the emerging openness to use online platforms in the museum context [5] and because of the lack of an overview of available features in research (see Section 2). In each empirical-toconceptual iteration, we adapted the taxonomy by analyzing online platforms with regard to their features. To achieve a robust taxonomy, two researchers (one with an IS background, one from Cultural Policy) independently examined each platform, identified the platform features and constantly consolidated their results in each iteration-uncertain cases were discussed. As a 1 st iteration, five museum websites were investigated and classified by the researchers. The results were consolidated and structured within the initial taxonomy. In the 2nd iteration, five further platforms (i.e., two rating platforms, one social media platform and two art blogs) were investigated, and the results were consolidated which inserted additional characteristics and adapted descriptions. As a $3 r d$ iteration, eleven further platforms (i.e., five art blogs, five museum websites and one social media platform) were analyzed. After discussing the results, it turned out that no changes in the taxonomy were necessary. As a 4th iteration (conceptual-to-empirical), the platform features identified during the literature review have been compared to the current version of the taxonomy (see Section 2). Apart from minor wording differences (e.g., linear search instead of user-driven search, non-linear search instead of a presentation of random cultural objects) that have been used for taxonomy description, no further features have been specified in the literature. Finally, the defined objective (o) and subjective (s) ending conditions were fulfilled by the taxonomy. In the following, we justify and contextualize the condition's degree of fulfillment (as suggested by [28]): (o1) A representative sample of objects (i.e., online platforms that allow cultural participation and education) has been examined; (o2) no object was merged or split in the last iteration; (o3) at least one object can be classified under every characteristic; (o4) no additional dimension/characteristic was necessary in the last iteration; (05) no dimensions/characteristics were merged or split in the last iteration; (o6) there is no dimension duplication; (07) as stated above, the characteristics are not unique within their dimension to offer features that can be used together on a platform; (o8) each cell is unique; (s1) the taxonomy is concise enough to be easily applied for the purpose of building an overview of currently used platform features that allow cultural participation and education; (s2) the taxonomy provide for differentiation among platform features; (s3) the taxonomy is comprehensive as all sample platforms 
can be classified; (s4) the taxonomy is easily extendible which allows considering novel platform features in this field; (s5) the current taxonomy sufficiently explains the currently used features for cultural participation and education (see also Section 5).

Stage 4: Taxonomy Evaluation. Fourthly, in addition to the development, taxonomies require extensive evaluation. Therefore, we draw on the evaluation framework for taxonomies [29] and follow guidelines for using taxonomy evaluation criteria [28]. We performed two initial evaluation steps, namely (1) illustrating the applicability of our taxonomy, and (2) ensuring the understandability and completeness of the taxonomy by utilizing several expert workshops (for more details see Section 5).

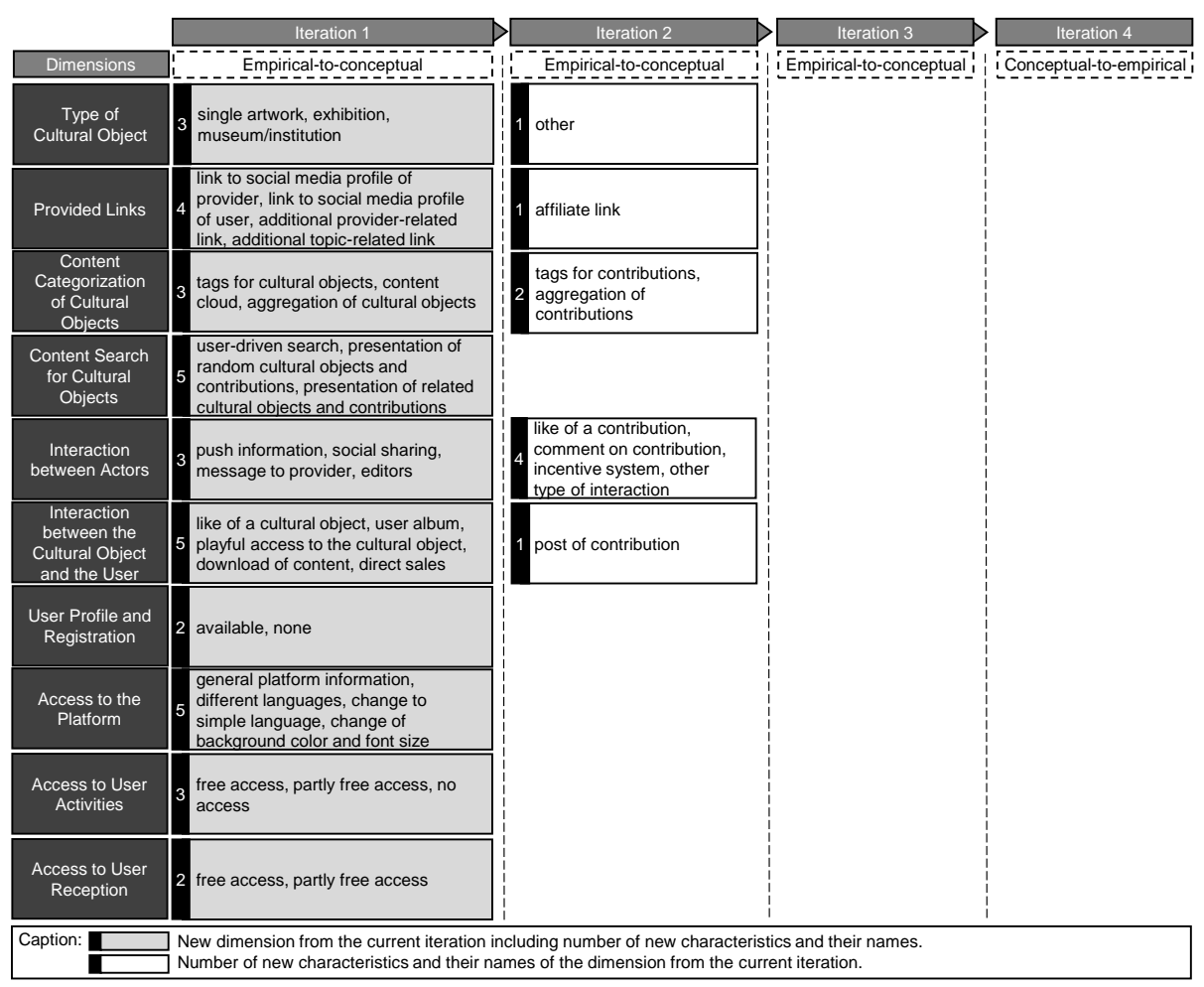

Figure 2. Evolution of dimensions and characteristics for the taxonomy

\section{Taxonomy of Digital Cultural Participation and Education}

Our taxonomy of 'Digital Cultural Participation and Education' contains ten dimensions, each with two to seven distinct characteristics (Figure 3). 


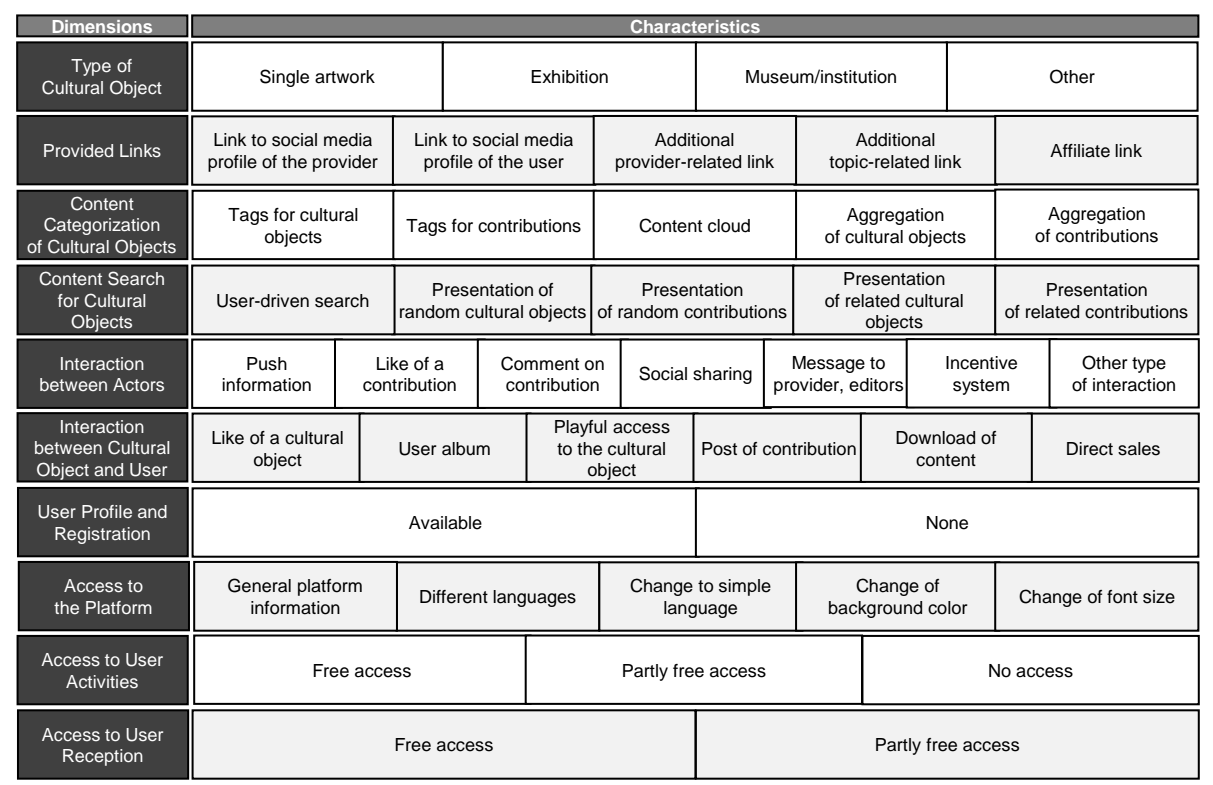

Figure 3. Taxonomy of digital cultural participation and education

In the following, we explain the taxonomy's dimensions and characteristics in more detail by providing descriptions as well as illustrative examples.

Type of Cultural Object. Online platforms provide access to multiple types of cultural objects for the general public: A single artwork such as a sculpture, a painting, or photography with information about its biographical contextualization, and sometimes detailed artist information are accessible online. Besides, a past, current, or future exhibition of a museum with its curator may be addressed. Moreover, the museum itself is presented with information about its history or current mission supplemented by practical visitor information. Sometimes, other cultural objects such as theatre, literature, or music are provided as well.

Provided Links. Furthermore, for allowing participation in the public and obtaining additional information, the platforms refer to further sources: Social media channels are connected to the platforms. For example, a museum (i.e., the provider of the platform) refers to its social media account. Besides, platform users can utilize their social media accounts, as platforms directly allow sharing artworks or publications via a social media button or they support the platform registration via the user social media accounts. Also, additional provider-related links are offered such as a reference on a museum website to a museum blog or other institutional websites. Furthermore, for providing more informative material, additional topic-related links to wikis, libraries, research databases, external blogs, schools or magazines, and affiliate links are offered.

Content Categorization of Cultural Objects. To provide an abstract view of cultural objects, platforms integrate content categorization: Cultural objects are assigned to tags such as the tags 'motive', 'image elements', or 'atmosphere' for artworks. Also, user reviews or articles on platforms (i.e., contributions) can be 
categorized by tags too. Additionally, content clouds are used, for instance, consisting of a multitude of miniature artwork images or topic-related keywords. To present some metric of the presented content, cultural objects or contributions are aggregated, for example, by showing the number of artworks of the digital collection or the number of user reviews.

Content Search for Cultural Objects. To find information on cultural objects, different features for information seeking within the data are provided: Platform users can access cultural objects, linear searching for content by terms. Sometimes, the platforms directly provide sample terms, or they complete terms after the user has started to write. Moreover, random cultural objects are displayed, usually on the first page, so that users randomly become aware of cultural objects and can seek information about them in the next step (i.e., creative, non-linear information search). Also, contributions are randomly presented and invite the platform user to read on. Viewing cultural objects or contributions, the platforms present related cultural objects or contributions which might be interesting for the user too. For instance, when a user views an artwork, he or she is provided with related artworks at the end of the page.

Interaction between Actors. A platform user, a platform provider or editors can potentially act on a platform and are supported to interact with each other, and thus, to participate in the society in several ways: A user may call for push information to receive regular news by registering for a newsletter or by 'liking' content on social media. Besides, actors' contributions can be assessed by a 'like-statement' or commented by actors, and content can be shared by users with others. If a user wants to give feedback to the provider or editors, a contact form or an email address are provided. Whereas some platforms actively ask for messages from their users, for instance, directly under an artwork presentation, others only mention an email address without a further call. To promote interaction between actors, incentive systems are introduced (e.g., a user receives points for activities like writing a review or answering to others and achieves a certain user level). Other types of interaction like a chat function, 'following others', or an offer/search forum are also provided.

Interaction between the Cultural Object and the User. Platforms not only make cultural objects accessible but also allow a certain degree of interaction between objects and the platform user: A user may assess an object by a 'like-statement' or by writing a contribution such as a review, comment, or the assignment of tags. Besides, users are allowed to build their customized album which contains their favorite cultural objects. Also, playful access to the cultural objects with the use of multimedia is provided: Users can view a series of artworks as a slideshow, they can view an exhibition through a video, they may zoom into an image in very high resolution, or they can take part in a virtual tour of the museum which may include 360-degree panoramic views and artworks of exhibitions. In addition, users can download content such as high-resolution copies of artworks, exhibition flyers, educative resources, or press material. Besides, direct sales of museum-related items, such as the exhibition catalog, publications, or image templates, are supported.

User Profile and Registration. Some platforms support registration and generation of a user profile so that users can participate on the platform. 
Access to the Platform. To get access to the platform at all, general platform information is provided which describes the essential features and tasks of the platform. Moreover, platform users can usually personalize the platform by choosing between different languages, and by changing the font size, the background color or the language into a simpler representation (i.e., use of less and simpler descriptions) via a button.

Access to User Activities. If a platform user is allowed to contribute content on a platform, he or she can either participate without restrictions (i.e., free access) or with some restrictions (i.e., partly free access). For instance, editorial staff checks the user's contribution before publication, or the user has to register before being active on a platform. However, users may have no access and are not allowed to contribute content.

Access to User Reception. Moreover, the public access to the platform content may vary: The platform content can be either completely visible for the general public without constraints (i.e., free access) or partly accessible (i.e., partly free access). Without registration, for example, every user can receive the content. In contrast, some information such as press material is only receivable after registration. Besides in some cases, user activities like a user album or a 'like-statement' on cultural objects are not visible to the public or the users themselves adjust the visibility of their activities.

\section{Demonstration and Evaluation}

For our preliminary evaluation, we describe two evaluation steps, namely illustrating the taxonomy's applicability as well as evaluating the taxonomy's understandability and completeness in more detail (see also Section 3).

Illustrating the Applicability. Applicability is often used as an evaluation criterion for taxonomies and supports investigating whether a taxonomy is applicable in practice which can be carried out, for instance, by classifying objects of the phenomenon of interest [28]. Therefore, two researchers classified two samples of online platforms through the taxonomy: All online platforms that have been used for taxonomy building and five additional art museum websites (i.e., K21 Kunstsammlung NordrheinWestfalen, Zentrum für Kunst und Medien Karslruhe, Marta Herford, Schirn Kunsthalle Frankfurt, Kunstmuseum Stuttgart). We thereby explored the distribution of features (i.e., which features are implemented by a platform). The results of the frequency analysis are outlined in Figure 4 by depicting the percentage of platform types (i.e., museum website, blog, social media, rating platform) that provide a feature.

In doing this, three main observations emerge: Firstly, none of the online platforms provide all of the identified features. Secondly, museums provide access to cultural objects, however, they hardly support the interaction between actors on their websites. They only provide newsletters as push information or allow messages to providers or editors via email. In addition, platform users are not allowed to post contributions such as reviews or comments or mostly cannot assess an object with a 'like-statement'. The discourse on cultural objects is, hence, outsourced to social media sites, blogs of art, and rating platforms. Thirdly, although a broad range of people should be able to get access and participate, only a few platforms support diverse ways of accessibility. Whereas most provide general information or the selection of other languages (e.g., to 
overcome language barriers), change to 'simple language' or customizing the background color or the font size are only rarely possible, which makes online cultural access problematic for individuals with disabilities. This is surprising, as accessibility is commonly addressed in the local museum policies (e.g., unrestricted access for all).

\begin{tabular}{|c|c|c|c|c|c|c|c|c|c|c|c|c|}
\hline Dimensions & \multicolumn{12}{|c|}{ Characteristics } \\
\hline $\begin{array}{l}\text { Type of } \\
\text { Cultural } \\
\text { Object }\end{array}$ & \multicolumn{3}{|c|}{$\begin{array}{c}\text { Single artwork } \\
\text { (m:100\%, b:100\%, s:75\%) }\end{array}$} & \multicolumn{3}{|c|}{$\begin{array}{c}\text { Exhibition } \\
\text { m: } 100 \% \text {, b: } 100 \% \text {, s: } 75 \%)\end{array}$} & \multicolumn{3}{|c|}{$\begin{array}{c}\text { Museum/institution } \\
\text { (m: } 100 \%, \mathrm{~b}: 86 \%, \mathrm{~s}: 100 \%)\end{array}$} & \multicolumn{3}{|c|}{$\begin{array}{c}\text { Other } \\
\text { (m: } 13 \%, \mathrm{~b}: 71 \%, \mathrm{~s}: 0 \%)\end{array}$} \\
\hline $\begin{array}{l}\text { Provided } \\
\text { Links }\end{array}$ & \multicolumn{2}{|c|}{$\begin{array}{l}\text { Link to social media } \\
\text { profile of the provider } \\
\text { (m:100\%, b:86\%, } \\
\mathrm{s}: 75 \%)\end{array}$} & \multicolumn{3}{|c|}{$\begin{array}{l}\text { Link to social media } \\
\text { profile of the user } \\
\text { (m: } 73 \%, b: 86 \% \\
\text { s: } 100 \%)\end{array}$} & \multicolumn{2}{|c|}{$\begin{array}{c}\text { Additional } \\
\text { provider-related link } \\
\text { (m: } 53 \%, b: 43 \%, \\
\mathrm{~s}: 100 \%)\end{array}$} & \multicolumn{3}{|c|}{$\begin{array}{c}\text { Additional } \\
\text { topic-related link } \\
\text { ( } \mathrm{m}: 87 \%, \mathrm{~b}: 100 \% \text {, } \\
\mathrm{s}: 75 \%)\end{array}$} & \multicolumn{2}{|c|}{$\begin{array}{c}\text { Affiliate link } \\
(\mathrm{m}: 33 \%, \mathrm{~b}: 14 \%, \mathrm{~s}: 50 \%)\end{array}$} \\
\hline $\begin{array}{l}\text { Content } \\
\text { Categorization } \\
\text { of Cultural } \\
\text { Objects }\end{array}$ & \multicolumn{2}{|c|}{$\begin{array}{l}\text { Tags for cultural } \\
\text { objects } \\
\text { (m: } 67 \%, \mathrm{~b}: 14 \% \\
\text { s: } 100 \%)\end{array}$} & \multicolumn{3}{|c|}{$\begin{array}{c}\text { Tags for } \\
\text { contributions } \\
\text { (m: } 7 \%, b: 100 \% \text {, } \\
\text { s: } 100 \%)\end{array}$} & \multicolumn{2}{|c|}{$\begin{array}{c}\text { Content cloud } \\
(\mathrm{m}: 7 \%, \mathrm{~b}: 14 \%, \mathrm{~s}: 0 \%)\end{array}$} & \multicolumn{3}{|c|}{$\begin{array}{c}\text { Aggregation } \\
\text { of cultural objects } \\
(\mathrm{m}: 73 \%, \mathrm{~b}: 0 \%, \mathrm{~s}: 50 \%)\end{array}$} & \multicolumn{2}{|c|}{$\begin{array}{c}\begin{array}{c}\text { Aggregation } \\
\text { of contributions } \\
\text { (m:0\%, b:57\%, s:100\%) }\end{array}\end{array}$} \\
\hline $\begin{array}{l}\text { Content } \\
\text { Search for } \\
\text { Cultural } \\
\text { Objects }\end{array}$ & \multicolumn{2}{|c|}{$\begin{array}{l}\text { User-driven search } \\
\text { (m:87\%, b:86\%, } \\
\text { s:100\%) }\end{array}$} & \multicolumn{3}{|c|}{$\begin{array}{c}\text { Presentation of } \\
\text { random cultural } \\
\text { objects } \\
\text { (m:100\%, b: } 100 \% \text {, } \\
\text { s: } 75 \% \text { ) } \\
\end{array}$} & \multicolumn{2}{|c|}{ 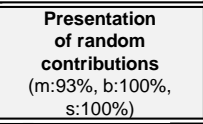 } & \multicolumn{3}{|c|}{$\begin{array}{c}\begin{array}{c}\text { Presentation } \\
\text { of related cultural } \\
\text { objects } \\
\text { (m: } 60 \%, \mathrm{~b}: 0 \%, \mathrm{~s}: 100 \%)\end{array} \\
\end{array}$} & \multicolumn{2}{|c|}{$\begin{array}{c}\begin{array}{c}\text { Presentation } \\
\text { of related } \\
\text { contributions } \\
\text { ( } \mathrm{m}: 47 \%, \mathrm{~b}: 71 \%, \mathrm{~s}: 50 \%)\end{array} \\
\end{array}$} \\
\hline $\begin{array}{l}\text { Interaction } \\
\text { between } \\
\text { Actors }\end{array}$ & $\begin{array}{c}\begin{array}{c}\text { Push } \\
\text { information } \\
(\mathrm{m}: 100 \%, \\
\mathrm{b}: 86 \%, \mathrm{~s}: 75 \%)\end{array} \\
\end{array}$ & \multicolumn{2}{|c|}{$\begin{array}{c}\text { Like of a } \\
\text { contribution } \\
(\mathrm{m}: 0 \%, \mathrm{~b}: 43 \% \\
\mathrm{s}: 100 \%)\end{array}$} & & $\begin{array}{l}\text { ment on } \\
\text { ribution } \\
\text { o, b: } 71 \% \text {, } \\
75 \%)\end{array}$ & \multicolumn{2}{|c|}{$\begin{array}{c}\text { Social sharing } \\
(\mathrm{m}: 13 \%, \mathrm{~b}: 0 \%, \\
\mathrm{s}: 75 \%)\end{array}$} & $\begin{array}{l}\text { Messag } \\
\text { provid } \\
\text { edito } \\
(\mathrm{m}: 100 \\
00 \%, \mathrm{~s}\end{array}$ & \begin{tabular}{|l|} 
to \\
r, \\
5 \\
0, \\
$00 \%)$ \\
\end{tabular} & \multicolumn{2}{|c|}{$\begin{array}{c}\text { Incentive } \\
\text { system } \\
\text { (m:0\%, b:0\%, } \\
\text { s: } 75 \%)\end{array}$} & $\begin{array}{c}\text { Other type } \\
\text { of interaction } \\
\text { (m:0\%, b: } 14 \% \text {, } \\
\mathrm{s}: 75 \%)\end{array}$ \\
\hline $\begin{array}{c}\text { Interaction } \\
\text { between } \\
\text { Cultural } \\
\text { Object and } \\
\text { User } \\
\end{array}$ & \multicolumn{4}{|c|}{\begin{tabular}{c|c}
$\begin{array}{c}\text { Like of a cultural } \\
\text { object }\end{array}$ & $\begin{array}{c}\text { User album } \\
\text { (m:33\%, b:0\%, } \\
\text { (m:20\%, b:0\%, } \\
\text { s:100\%) }\end{array} \quad$ s:100\%) \\
\end{tabular}} & \multicolumn{2}{|c|}{$\begin{array}{c}\text { Playful access } \\
\text { to the cultural } \\
\text { object } \\
\text { (m:93\%, b:29\%, } \\
\text { s:50\%) } \\
\end{array}$} & \multicolumn{2}{|c|}{$\begin{array}{c}\begin{array}{c}\text { Post of } \\
\text { contribution }\end{array} \\
\text { (m:0\%, b:29\%, } \\
\mathrm{s}: 100 \%) \\
\end{array}$} & \multicolumn{3}{|c|}{$\begin{array}{c}\text { Download of } \\
\text { content } \\
\text { (m:93\%, b:14\%, } \\
\text { s: } 25 \% \text { ) }\end{array}$} & $\begin{array}{c}\text { Direct sales } \\
\text { (m:93\%, b:14\%, } \\
\text { s:50\%) }\end{array}$ \\
\hline $\begin{array}{l}\text { User Profile } \\
\quad \text { and } \\
\text { Registration }\end{array}$ & \multicolumn{6}{|c|}{$\begin{array}{c}\text { Available } \\
\text { (m:53\%, b:43\%, s:100\%) }\end{array}$} & \multicolumn{6}{|c|}{$\begin{array}{c}\text { None } \\
(\mathrm{m}: 47 \%, \mathrm{~b}: 57 \%, \mathrm{~s}: 0 \%)\end{array}$} \\
\hline $\begin{array}{l}\text { Access to } \\
\text { the Platform }\end{array}$ & \multicolumn{2}{|c|}{$\begin{array}{c}\text { General platform } \\
\text { information } \\
\text { (m: } 47 \%, b: 100 \% \text {, } \\
\mathrm{s}: 100 \%)\end{array}$} & \multicolumn{3}{|c|}{$\begin{array}{l}\text { Different languages } \\
\text { (m:100\%, b:57\%, } \\
\text { s: } 100 \%)\end{array}$} & \multicolumn{2}{|c|}{$\begin{array}{l}\text { Change to simple } \\
\text { language } \\
(\mathrm{m}: 7 \%, \mathrm{~b}: 0 \%, \mathrm{~s}: 0 \%)\end{array}$} & \multicolumn{3}{|c|}{$\begin{array}{c}\begin{array}{c}\text { Change of } \\
\text { background color } \\
(\mathrm{m}: 7 \%, \mathrm{~b}: 0 \%, \mathrm{~s}: 25 \%)\end{array}\end{array}$} & \multicolumn{2}{|c|}{$\begin{array}{l}\text { Change of font size } \\
(\mathrm{m}: 7 \%, \mathrm{~b}: 0 \%, \mathrm{~s}: 25 \%)\end{array}$} \\
\hline $\begin{array}{l}\text { Access to } \\
\text { User } \\
\text { Activities }\end{array}$ & \multicolumn{4}{|c|}{$\begin{array}{c}\text { Free access } \\
\text { (m:13\%, b:43\%, s:50\%) }\end{array}$} & \multicolumn{4}{|c|}{$\begin{array}{c}\text { Partly free access } \\
\text { (m:20\%, b:29\%, s:50\%) }\end{array}$} & \multicolumn{4}{|c|}{$\begin{array}{c}\text { No access } \\
(\mathrm{m}: 67 \%, \mathrm{~b}: 28 \%, \mathrm{~s}: 0 \%)\end{array}$} \\
\hline $\begin{array}{l}\text { Access to } \\
\text { User } \\
\text { Reception }\end{array}$ & & $\begin{array}{r}\mathbf{F} \\
\mathrm{m}: 53 \%\end{array}$ & $\begin{array}{l}\text { Free acce } \\
\%, \mathrm{~b}: 100 \%\end{array}$ & s: s:50 & & & & & $\begin{array}{l}\text { Partl } \\
\text { m:47\% }\end{array}$ & $\begin{array}{l}\text { free acce } \\
b, \mathrm{~b}: 0 \%, \mathrm{~s}:\end{array}$ & $\begin{array}{l}\text { ess } \\
50 \%)\end{array}$ & \\
\hline & & & & & Caption & & $\begin{array}{r}\text { frequ } \\
\text { um webs }\end{array}$ & & butic & $\begin{array}{l}7 \text { feature } \\
\text { of the feat } \\
\text { ocial medi }\end{array}$ & $\begin{array}{ll}\text { ture } \\
\text { ia sit }\end{array}$ & $\begin{array}{l}\text { \% on: } \\
\& \text { rating platform) }\end{array}$ \\
\hline
\end{tabular}

Figure 4. Distribution of platform features

Evaluating the Understandability and Completeness. To obtain insights in terms of the taxonomy's understandability and completeness for the intended target users and purposes [12, 29], we conducted workshops with three experts. We invited three researchers who were not involved in the taxonomy development process and who have already performed research on online platforms including cultural and educational concerns-i.e., potential target users of the taxonomy (see Section 3, Stage 3). As understandability is a prerequisite for the correct usage of a taxonomy, a positive 
answer would be an indication of its usefulness [29]. Therefore, the workshop participants were asked to describe the taxonomy (e.g., what is meant by each element), to assess the taxonomy's understandability and if necessary to make suggestions for improving the taxonomy. The participants stated that most dimensions and characteristics are self-explanatory and only some wording should be adjusted to strengthen the interpretability and understandability of the taxonomy. For example, one participant assessed upper categories (i.e., provision of content, interaction, accessibility) as ambiguous and thus difficult to understand. Another participant suggested to change the term 'findability of content' to 'content search', 'other' to 'additional' for some characteristics of the dimension 'provided links' and 'feedback to editors' to 'message to provider, editors'. Furthermore, the participant recommended changing the order of dimensions. Moreover, the majority of participants we asked to evaluate the completeness of the taxonomy, did not see the necessity to add further elements. Only one suggestion included that the characteristic 'accessibility for user with disability' should be split and more differentiated in the next version of the taxonomy. After discussing the results within the author team, we decided to adapt these points and to revise the current version of the taxonomy accordingly.

\section{Discussion}

Museums play a fundamental role in enabling our society to access, engage with and learn about the cultural heritages but simultaneously face challenges in achieving this mission because of diverse hurdles on an individual but also social and environmental level. Against this backdrop, the booming digitalization [30] provides promising tools such as platforms and social media that can be adapted from museums to develop new strategies for providing cultural participation and education. In attempting to leverage this potential, we sought to explore what are the characteristic features of online platforms providing this participation and education and present a taxonomy of Digital Cultural Participation and Education. Our taxonomy provides an overview of features for such platforms that can be employed to make more informed design decisions in terms of museum platforms as well as lays the ground for future endeavors. We believe that this study is an important step towards how online platforms can improve access to cultural participation and education, which has implications for theory and practice and opens avenues for future research. Next, we discuss four of those avenues.

Enhancing the Possibilities of Interaction on Museum Websites. During the platform analysis, we found that all museums provide access to their cultural objects on their websites, for example, by providing an online collection of multiple artworks with detailed artist information. Furthermore, the majority (93\%) allows a playful access to these objects (e.g., users can take part in a virtual tour of the museum or can zoom into an artwork with high resolution). As the use of multimedia and interactive components may lead to enjoyment and informal online learning in the context of museums $[10,16]$, such a playful access presents potential with participatory and educational relevance. However, museums hardly support their platform users to interact with cultural objects in different ways, users are not allowed to post 
contributions such as online reviews or comments and mostly cannot assess an object with a 'like-statement' (only $20 \%$ of museum websites provides such a feature). Moreover, although establishing social interaction can be seen as a recommended museum website feature $[10,15]$, we observed that the majority of museum websites only provides newsletter as push information or supports messages to providers/editors and does not allow for interacting with others (e.g., none of them allow liking and commenting contributions). This is in line with [5] who explains that few museums open their websites for users' comments. The discourse on cultural objects and the interaction between users are, hence, outsourced to social media sites, blogs of art, and rating platforms. However, despite the higher level of support for interaction, we observed that such platforms usually arrange the contributions chronologically, placing older contributions far below which might lead to increased search effort for the users. Therefore, as all museums provide access to cultural objects on their websites and thus provide an enormous foundation for consumption and community activities, we would encourage practitioners to pay more attention to these features of interaction, to entirely allow cultural participation and experiences.

Providing Diverse Ways of Accessibility of Cultural Participation. While examining the platforms, we mostly missed different ways of accessibility of cultural participation for a broad range of people (e.g., individuals with visual or cognitive impairments) such as 'change to simple language', 'change of background color' and 'change of font size'. Although such personalization is considered to be an important museum website feature [14], we found that the majority of platforms only implements a feature for selecting different languages. This is surprising, as unrestricted access is commonly addressed in the local museum policies. To advance the challenges of Digital Inclusion [31] and to contribute to the social sustainability of cultural platforms [32], we call for the provision of cultural participation accessible for all individuals.

Investigating Cultural Differences and Integration of Practitioners. Focusing on art museums, we analyzed various online platforms (e.g., museum websites, rating platforms) that provide access to cultural participation. Considering further platforms and research findings, for instance, in the non-German context, platforms of different museum types (e.g., museum of local history or natural history [27]) or platforms of further institutions with cultural and educational missions (e.g., theatre, libraries), may support verifying or extending our results. It might be interesting, for example, to investigate differences in cultural access depending on the region. Moreover, in line with Nickerson's et al. [12] proposal to "query users about their potential use of (a) taxonomy", we plan to conduct a case study with a local museum-i.e., a potential target user of the taxonomy in practice (see Section 3, Stage 3). In doing so, we aim to indicate that the taxonomy is useful for its intended purpose, namely, for providing an overview of platform features and for comparing, refining, or developing platforms. In addition, we want to find out to what extent the currently used platform features enable the best possible access to cultural objects as well as the increase of opportunities for cultural participation and education. Case studies "involve intensive research on a phenomenon (a case) within its natural setting (one or more case sites) over a period of time" [33], which, referring to this study, allows exploring how the taxonomy works in a natural environment. 
Transferring Existing Knowledge from Cultural Education to Platforms. To promote cultural education through online platforms [34], existing knowledge from education in cultural practices, such as in arts, architecture, or music, may be transferred to the digital space. Doing so, considering best-practices, literature, and theoretical approaches on cultural education can serve as a source of knowledge as it might provide criteria for online platforms and, hence, support in confirming, refining or identifying further platform features. As a valuable source, Marotzki's approach of structural education theory might give insights for the platform design. It undertakes educational processes as transformations of relations to oneself and the world [35] and education itself comprises reflective, problematizing confrontations with (a) oneself, (b) others and things, as well as (c) themes of the world [3]. Referring to the taxonomy, for instance, (a) the building of a user profile is available, which might contribute to statements about the user's identity. Also, (b) sharing opinions and communicating with others is allowed which might influence the user's relationship with others. Moreover, (c) intensively reflecting on cultural objects, forming and changing opinions as well as contextualizing artworks, could change the individuals' relation to the world. These are initial ideas to promote online platforms leveraging cultural education. In this way, one can search for and use a theoretical foundation for deriving/revising features for such online platforms.

In addition, methodical limitations apply to our study. Searching for relevant IS literature, appertaining to museum online platforms, we identified studies that investigated museum websites and platform features. Our literature search is however limited to the selected database, other online databases such as Google Scholar and EBSCO may reveal further data. As another limitation, we primarily collected platform features for providing access to cultural participation and education, thereby did not examine to what extent the features enable the best possible access.

\section{Conclusion}

Drawing on a literature review and the analysis of museum online platforms we derived and evaluated a taxonomy of Digital Cultural Participation and Education. This taxonomy structures several platform features that provide access to cultural objects, cultural participation as well as education. Overall, the results contribute to research on museum practice in digitization and illustrate a number of museum-specific platform features which are used with varying frequency (see Demonstration). For example, users can build their customized album with their favorite cultural objects, they can take part in a virtual tour of the museum, or they can zoom into an artwork with high resolution. In addition, we found that museums shift the discourse to social media, blogs or rating platforms and, for instance, seldom support diverse ways of accessibility (e.g., change to 'simple language', customizing the background color) to support an unrestricted access for all individuals. These results can be used to derive implications for a new generation of (social inclusive) online platforms that seek to fulfill their mission of cultural and educational participation (e.g., by means of virtual and augmented reality). Moreover, while this study is anchored in the museum context, and 
therefore, develops knowledge for a specific class of artifacts, it enables further research to understand how a broader class of online platforms need to be adapted for specific contexts. Along with this, it seems fruitful to investigate the applicability of (a subset of) the proposed platform features in further domains.

Ultimately, by shedding light on the importance of accessibility to and participation in cultural information, we hope to boost online access to cultural objects and facilitate cultural participation as well as education - in particular, to face the challenges of the Covid-19 pandemic, leading to the closure of plenty of museum facilities in 2019/20.

\section{Acknowledgements}

This research was conducted in the scope of the research project "Rez@Kultur" (01JKD1703), which is funded by the Bundesministerium für Bildung und Forschung (BMBF). We would like to thank them for their support.

\section{References}

1. ICOM: ICOM Code of ETHICS for Museums, https://icom.museum/wpcontent/uploads/2018/07/ICOM-code-En-web.pdf (Accessed 18.04.2020)

2. ICOM: Creating a New Museum Definition - the Backbone of ICOM, https://icom.museum/en/resources/standards-guidelines/museum-definition/ (Accessed 25.11.2020)

3. Fuchs, T.: Education and Biography: A Reformulation of Biography Research Oriented on Education Theory [Original: Bildung und Biographie: Eine Reformulierung der bildungstheoretisch orientierten Biographieforschung]. transcript, Bielefeld (2011)

4. Treptow, R.: Above all, all Visitors are Equal. Cultural Education Processes in the Museum Order [Original: Vor den Dingen sind alle Besucher gleich. Kulturelle Bildungsprozesse in der musealen Ordnung]. Zeitschrift für Pädagogik. 51(6), 797-809 (2005)

5. Lotina, L.: Reviewing Museum Participation in Online Channels in Latvia. In: Kristiansen, E. (ed.) Proceedings of the DREAM Conference The Transformative Museum, pp. 188-195. DREAM - Danish Research Center on Education and Advanced Media Materials, Roskilde, Denmark (2012)

6. Srinivasan, R., Boast, R., Furner, J., Becvar, K.M.: Digital Museums and Diverse Cultural Knowledges: Moving Past the Traditional Catalog. The Information Society. 25(4), 265278 (2009)

7. Moon, S.: Effects of COVID-19 on the Entertainment Industry. International Digital Organization for Scientific Research. IDOSR Journal of Experimental Sciences. 5(1), 8-12 (2020)

8. Tim, Y., Pan, S.L., Ouyang, T.: Museum in the Age of Digital Transformation. In: Proceedings of the 22th Pacific Asia Conference on Information Systems, Yokohama, Japan (2018)

9. Baumgärtner, T.: Conceptualizing a Mobile App Framework for the Museum Application Domain. In: Proceedings of the 27th European Conference on Information Systems (ECIS), Stockholm \& Uppsala, Sweden (2019) 
10. Lin, A.C.H., Fernandez, W., Gregor, S.: Designing for Enjoyment and Informal Learning: A Study in A Museum Context. In: Proceedings of the Pacific Asia Conference on Information Systems (PACIS), Taipei, Taiwan (2010)

11. Wray, T., Eklund, P., Kautz, K.: Pathways through Information Landscapes: Alternative Design Criteria for Digital Art Collections. In: Proceedings of the 34th International Conference on Information Systems (ICIS), Milano, Italy (2013)

12. Nickerson, R.C., Varshney, U., Muntermann, J.: A Method for Taxonomy Development and its Application in Information Systems. European Journal of Information Systems. 22(3), 336-359 (2013)

13. Pallud, J., Straub, D.W.: The "Love of Art" vs. Website Design: An Application of Bourdieu's Theory in Online Environments. In: Proceedings of the 14th Americas Conference on Information Systems (AMCIS), Toronto, Ontario, Canada (2008)

14. García-Madariaga, J., Recuero Virto, N., Blasco López, F.: The Influence of Museums' Websites on Users' Intentions. Esic Market Economics and Business Journal. 48(2), 369392 (2017)

15. Lin, A.C.H., Gregor, S.: Designing Websites for Learning and Enjoyment: A Study of Museum Experiences. International Review of Research in Open and Distance Learning. 7(3), 1-22 (2006)

16. Lin, A.C.H., Gregor, S., Huang, J.C.C.: The Hedonic Experience of Enjoyment and its Relationship to Informal Learning: A Study of Museum Websites. In: Proceedings of the 29th International Conference on Information Systems (ICIS), Paris, France (2008)

17. Windhager, F., Federico, P., Mayr, E., Schreder, G., Smuc, M.: A Review of Information Visualization Approaches and Interfaces to Digital Cultural Heritage Collections. In: Aigner, W., Schmiedl, G., Blumenstein, K., Zeppelzauer, M. (eds.) Proceedings of the 9th Forum Media Technology (FMT2016). St. Pölten University of Applied Sciences, Institute of Creative Media Technologies, St. Pölten, Austria (2016)

18. Carugati, A., Hadzilias, E., Demoulin, N.: Setting the Framework for Developing eGovernment Services on Cultural Heritage. In: Proceedings of the 13th European Conference on Information Systems (ECIS), Regensburg, Germany (2005)

19. Remane, G., Nickerson, R., Hanelt, A., Tesch, J.F., Kolbe, L.M.: A Taxonomy of Carsharing Business Models. In: Proceedings of the 37th International Conference on Information Systems (ICIS), Dublin, Ireland (2016)

20. Szopinski, D., Schoormann, T., John, T., Knackstedt, R., Kundisch, D.: Software Tools for Business Model Innovation: Current State and Future Challenges. Electronic Markets. (2019)

21. Katsma, C., Spil, T.: A Taxonomy of Digital Music Services. In: Proceedings of the 16th Americas Conference on Information Systems (AMCIS), Lima, Peru (2010)

22. Kutzner, K., Petzold, K., Knackstedt, R.: Characterising Social Reading Platforms - A Taxonomy-Based Approach to Structure the Field. In: Proceedings of the 14th International Conference on Wirtschaftsinformatik, pp. 676-690, Siegen, Germany (2019)

23. Foni, A.E., Papagiannakis, G., Magnenat-Thalmann, N.: A Taxonomy of Visualization Strategies for Cultural Heritage Applications. ACM Journal on Computing and Cultural Heritage. 3(1), (2010).

24. Gregor, S.: The Nature of Theory in Information Systems. MIS Quarterly. 30(3), 611-642 (2006)

25. vom Brocke, J., Simons, A., Niehaves, B., Reimer, K., Plattfaut, R., Cleven, A.: Reconstructing the Giant: on the Importance of Rigour in Documenting Literature Search Process. In: Proceedings of the European Conference on Information Systems (ECIS), Verona, Italy (2009) 
26. $\mathrm{Hu}, \mathrm{S}$., Mou, J.: Impacts of Social Media Usage in Cross-cultural Social Commerce: the Roles of Cultural Intelligence and Cultural Distance. In: Proceedings of the 19th Wuhan International Conference on E-Business - Cross-cultural E-commerce (2020)

27. Institut für Museumsforschung: Statistical Survey of Museums of the Federal Republic of Germany for the Year 2018 [Original: Statistische Gesamterhebung an den Museen der Bundesrepublik Deutschland für das Jahr 2018], Berlin, Germany (2019)

28. Szopinski, D., Schoormann, T., Kundisch, D.: Criteria as a Prelude for Guiding Taxonomy Evaluation. In: Proceedings of the 53rd Hawaii International Conference on System Sciences (HICSS) (2020)

29. Szopinski, D., Schoormann, T., Kundisch, D.: Because Your Taxonomy is Worth It: Towards a Framework for Taxonomy Evaluation. In: Proceedings of the 27th European Conference on Information Systems (ECIS), Stockholm-Uppsala, Sweden (2019)

30. Kutzner, K., Schoormann, T., Knackstedt, R.: Digital Transformation in Information Systems Research: A Taxonomy-based Approach to Structure the Field. In: Proceedings of the 26th European Conference on Information Systems (ECIS), Portsmouth, England (2018)

31. Digital Inclusion Team: Digital Inclusion Team [Electronic Version], http://digitalinclusion.pbwiki.com/ (Accessed: 24.11.2020) (2007)

32. Schoormann, T., Kutzner, K.: Towards Understanding Social Sustainability: An Information Systems Research-Perspective. In: Proceedings of the 41th International Conference on Information Systems (ICIS), Hyderabad, India (2020)

33. Recker, J.: Scientific Research in Information Systems. Springer, Berlin, Heidelberg, Germany (2013)

34. UNESCO Institute for Statistics: The 2009 UNESCO Framework for Cultural Statistics (FCS), Montreal, Quebec, Canada (2009)

35. Marotzki, W.: Design of a Structural Education Theory: Biography-Theoretical Interpretation of Educational Processes in Highly Complex societies [Original: Entwurf einer strukturalen Bildungstheorie: biographietheoretische Auslegung von Bildungsprozessen in hochkomplexen Gesellschaften]. Deutscher Studien Verlag, Weinheim, Germany (1990) 